\title{
Comparison of Clinical Examination and Various Imaging Modalities in the Diagnosis of Head and Neck Cancer
} \author{
Barbara Wollenberg ${ }^{5}$ Jens Eduard Meyer ${ }^{4}$ \\ 1 Department of Radiology, Klinikum Gütersloh, Gütersloh, Germany \\ 2 Department of Otorhinolaryngology, Head and Neck Surgery, St. \\ Joseph-Stift, Bremen, Germany \\ ${ }^{3}$ Department of Otorhinolaryngology, Head and Neck Surgery, \\ Universitätsklinikum Schleswig-Holstein, Kiel, Germany \\ ${ }^{4}$ Department of Otorhinolaryngology, Head and Neck Surgery, \\ Asklepios Clinic St. Georg, Hamburg, Germany \\ ${ }^{5}$ Department of Otorhinolaryngology, Head and Neck Surgery, \\ Universitätsklinikum Schleswig-Holstein, Lübeck, Germany
}

Uwe Schneider $^{10}$ Inse Graß ${ }^{2}$ Martin Laudien ${ }^{3} \quad$ Joachim Quetz $^{3}$ Hendrik Graefe ${ }^{4}$

Int Arch Otorhinolaryngol 2021;25(2):e179-e184.
Address for correspondence Jens Eduard Meyer, MD, PhD, Asklepios Clinic St. Georg, Lohmühlenstraße 5, 20099 Hamburg, Germany (email: jens.meyer@asklepios.com).

\section{Abstract \\ Introduction Squamous cell Carcinoma of the Head and Neck (HNSCC) is the most common tumor entity of malignant processes in the head and neck area. Due to the metastasizing behavior of these tumors, the staging is indispensable for the treatment planning and requires imaging techniques, which are sensitive, specific, and as far as possible cost-effective, to benefit ultimately the patient and to ensure optimal care. Objectives The aim of the present study is to compare the clinical examination including palpation, ultrasound and computed tomography (CT)/magnetic resonance imaging (MRI) for the diagnosis of neck metastases to make the correct indication for a neck dissection. \\ Methods Data from 286 patients with HNSCC were analyzed for neck metastases to determine which diagnostic tool is the best to answer the question if a neck dissection is necessary or not. Each study method was examined retrospectively by comparing sensitivity, specificity, the positive/negative predictive value, the positive likelihood ratio and the diagnostic accuracy. \\ Keywords \\ - cancer of head and neck \\ - ultrasound imaging \\ - X-ray computed tomography \\ - MR tomography \\ - neck dissections \\ Results The ultrasound showed a sensitivity of $91.52 \%$, a specificity of $61.67 \%$, a positive/negative predictive value of $76.65 \% / 84.09 \%$, a positive likelihood ratio of 2.39 and a diagnostic accuracy of $78.95 \%$. The clinical examination showed a sensitivity of $75.76 \%$, a specificity of $66.12 \%$, a positive/negative predictive value of $75.30 \% / 66.67 \%$, a positive likelihood ratio of 2.24 and a diagnostic accuracy of $71.68 \%$. The CT/MRI showed a sensitivity of $78.66 \%$, a specificity of $62.50 \%$, a positive/negative predictive value of $74.14 \%$ / $68.18 \%$, a positive likelihood ratio of 2.10 and a diagnostic accuracy of $71.83 \%$. Radio- graphically, ultrasound, as well as the clinical examination, could be judged to be free from}

received

August 30, 2018

accepted

October 20, 2019

published online

May 13, 2020
DOI https://doi.org/

10.1055/s-0039-3402435. ISSN 1809-9777. (c) 2020. Fundação Otorrinolaringologia. All rights reserved.

This is an open access article published by Thieme under the terms of the Creative Commons Attribution-NonDerivative-NonCommercial-License, permitting copying and reproduction so long as the original work is given appropriate credit. Contents may not be used for commercial purposes, or adapted, remixed, transformed or built upon. (https://creativecommons.org/ licenses/by-nc-nd/4.0/)

Thieme Revinter Publicações Ltda., Rua do Matoso 170, Rio de Janeiro, RJ, CEP 20270-135, Brazil 
radiation load and side effects from the contrast medium. The high dependence on the investigator when using ultrasound made reproducibility of the results difficult.

Conclusions It could be shown that ultrasound was the diagnostic tool with the highest sensitivity, positive/negative predictive value, positive likelihood ratio and diagnostic accuracy by detecting and interpreting metastases in the head and neck region correctly. Whether a neck dissection should be performed depends to a large extent on the ultrasound findings.

\section{Introduction with Objective(s)}

Squamous cell Carcinoma of the Head and Neck (HNSCC) is the sixth most common malignant disease in the world. ${ }^{1}$ Carcinomas of the oral cavity and of the pharynx cause 200,000 deaths each year, and the incidence is up to 363,000 new cases yearly. ${ }^{2}$

The prognosis of the patient depends to a large extent on the lymph node status. ${ }^{3}$ If regional lymph nodes are affected, the 5-year-overall-survival decreases to up to $50 \%$. Bilateral lymph node involvement regresses survival by $75 \%$, and an additional extranodal involvement reduces survival by a further $50 \%{ }^{2}$

If indicated, the cervical lymph nodes are removed in a selective or radical neck dissection. Continuing postoperative treatment by radiotherapy or chemotherapy depends on the histopathological result of the lymph nodes removed. ${ }^{3}$

Due to the metastasizing behavior of the tumors in the head and neck area, the staging requires imaging techniques, which are sensitive, specific and, as far as possible, costeffective, to benefit ultimately the patient and to ensure optimal care.

Traditionally, clinical examination with inspection and palpation is the initial procedure, ultrasound imaging is then applied and complemented by imaging techniques such as computed tomography (CT) and magnetic resonance imaging (MRI). ${ }^{3}$

The aim of the present study is to compare the clinical examination including palpation, ultrasound, and CT/MRI for the diagnosis of neck metastases to make the correct indication for a neck dissection. For this purpose, the dependency of sensitivity, specificity, positive or negative predictive value, positive likelihood ratio and diagnostic accuracy on the final histopathological result after neck dissection were examined.

\section{Method}

\section{Patient Population}

The data used in the present study were collected during the period between 1989 and 2004 and was summarized in a database. The patients have agreed to the retrospective collection and further processing of the data by informed consent. The data collection and the further processing of the anonymized data were approved by the local ethics committee (approval number/ID: 22/93 and 11-080A).
All of the patients were examined clinically, by bilateral ultrasound and $\mathrm{CT}$ and/or MRI for neck metastases. Following these diagnostic procedures, in all patients with a positive screening, a unilateral or bilateral elective neck dissection was performed and suspicious lymph nodes according to levels were histopathologically examined to determine their malignancy. Each patient had a documented follow-up period of at least 10 years. Both the results of the diagnosis as well as the surgery/pathology were divided into levels according to the lymph node classification of Robbins to make an exact classification of the diagnostic and pathological results. Finally, the various diagnostic results were statistically worked up and compared with each other for their diagnostic accuracy.

\section{Clinical Examination}

The palpation was performed bimanually in comparison to the contralateral side with the fingertips from a position behind the sitting patient.

\section{Ultrasound Imaging}

In the present study, we used a Siemens Sonoline Versa machine and a frequency probe of $7.5 \mathrm{MHz}$. The patient was positioned on his back and extended his neck during the examination. Suspicious findings were examined in at least two planes.

For the determination of malignancy, the following sonomorphological features were investigated: longitudinal diameter, maximal and minimal transverse diameter, ratio of both transverse diameters to one another, ratio of longitudinal to transverse diameter, volume, echocoic structure, presence of a hilum sign.

\section{Computed Tomography and Magnetic Resonance Imaging}

In the present study, the CT used was an Emotion Duo device and the MRI was performed with a Siemens device with 1 and 1.5 Tesla. The CT scan was performed with contrast-medium, the MRI was conducted native.

\section{Statistical Analysis}

The patient-specific data were compiled in a database and then processed further. To be able to answer the hypothesized questions and to compare the various diagnostic results with their statistical parameters, calculation of sensitivity (SENS) and specificity (SPEC), positive predictive value (PPV), the negative predictive value (NPV), the positive likelihood ratio and the diagnostic accuracy of the investigation was 
performed. For this purpose, it was determined which of the 286 patients had a suspicious finding in the clinical examination, the ultrasound or the CT/MRI. Subsequently, the respective statistical parameters were calculated using a four-panel tablet.

\section{Result}

We obtained 38 T1-stage (13.3\%), 106 T2-stage (37.1\%), 58 T3stage $(20.3 \%)$ and 46 T4-stage (16.1\%). A total of 14 datasets were incomplete. Therefore, most tumors can be assigned to the T2-stage. The N-stage shows 115 primary tumors (40.2\%) without regional lymph node metastases. A total of 39 specimens (13.6\%) indicate an N1-stage. Furthermore, 115 neck dissections (40.2\%) were classified as N2-stage, of which 15 (5.2\%) were N2a, 72 (25.2\%) N2b, and, finally, 28 (9.8\%) were N2c-stage. Three preparations (1.0\%) were diagnosed as N3stage, and 2 preparations ( $0.7 \%$ ) could not be assessed (Nx). There are no details for 12 values. A total of $94.8 \%$ (271) of the preparations were linked to the M0-stage, which means that there are no distant metastases. In 2.4\% (7), no assessment of distance metastasis was possible (Mx) and 8 datasets were not given (-Table 1 ).

A total of 238 neck metastases (83.2\%) were defined as squamous cell carcinomas, which are most frequently represented. In this category, 135 were $\mathrm{N}+, 100$ were $\mathrm{N}-$, and 3 were $\mathrm{Nx}$. The second most common were adenocarcinomas, which occurred in 8 cases $(2.8 \%)$, while mucoepidermoid carcinomas occurred in 7 cases (2.4\%). Five tumors (1.7\%) were lymphoepithelial carcinomas/Schmincke tumors, 4 tumors $(1.4 \%)$ were melanomas, and $3(1.0 \%)$ of the tumors were lymphomas (-Table 2 ).

The diagnosis of a metastasis is correct and the absence of a metastasis is recognized correctly. As a result, the correct diagnosis can be made 2.39 times more frequently than the other imaging modalities ( - Table $\mathbf{3}$ ).

\section{Discussion}

The primary tumor localization is the area of the oropharynx (35.3\%). The second most common tumors are in the area of the glottic space (14.0\%) and the tumors of the lymphatic/ hematologic system are the third most frequent tumor sites (10.1\%) in our study group. This is followed by tumors of the

Table 1 TNM stages of the Study cohort $(N=286)$

\begin{tabular}{|l|l|l|l|l|l|l|l|}
\hline \multicolumn{2}{|c|}{} & \multicolumn{2}{l}{ N } & \multicolumn{2}{l|}{ M } \\
\cline { 3 - 8 } \multicolumn{2}{|c|}{} & N+ & N- & Nx & M+ & M- & Mx \\
\hline \multirow{4}{*}{$T$} & 1 & 18 & 15 & 5 & 0 & 36 & 2 \\
\cline { 2 - 8 } & 2 & 47 & 58 & 1 & 0 & 105 & 1 \\
\cline { 2 - 8 } & 3 & 32 & 26 & 0 & 0 & 57 & 1 \\
\cline { 2 - 8 } & 4 & 33 & 13 & 0 & 0 & 45 & 1 \\
\cline { 2 - 8 } & Tx & 27 & 3 & 8 & 0 & 28 & 10 \\
\hline
\end{tabular}

Abbreviations: M, distant metastasis; N, nodi according to pathological findings after neck dissection; T, tumor; $\mathrm{X}$, No information.
Table 2 The most common tumor entities in the patient sample $(n=286)$

\begin{tabular}{|l|l|}
\hline Tumor entities & $\begin{array}{l}\text { Number (absolute values) } \\
\text { of the tumor entities }\end{array}$ \\
\hline $\begin{array}{l}\text { Squamous cell } \\
\text { carcinoma (83.2\%) }\end{array}$ & 238 \\
\hline Adenocarcinoma (2.8\%) & 8 \\
\hline $\begin{array}{l}\text { Mucoepidermoid } \\
\text { carcinoma (2.4\%) }\end{array}$ & 7 \\
\hline $\begin{array}{l}\text { Lymphoepithelial/ } \\
\text { Schmincketumor (1.7\%) }\end{array}$ & 5 \\
\hline Melanoma (1.4\%) & 4 \\
\hline $\begin{array}{l}\text { Lymphoma, not further } \\
\text { described (1.0\%) }\end{array}$ & 3 \\
\hline $\begin{array}{l}\text { Carcinoma in } \\
\text { adenoma (0,7\%) }\end{array}$ & 2 \\
\hline $\begin{array}{l}\text { Adenoidcystical } \\
\text { carcinoma (0,4\%) }\end{array}$ & 1 \\
\hline Sarcoma (0,4\%) & 1 \\
\hline $\begin{array}{l}\text { Undifferentiated } \\
\text { carcinoma (0,4\%) }\end{array}$ & 1 \\
\hline Acinuscell-carcinoma (0,4\%) & 1 \\
\hline No information (5,2\%) & 15 \\
\hline
\end{tabular}

oral cavity, hypopharynx and the supraglottic region, each with the same number of absolute values (24), which corresponds to $8.4 \%$. The last site with absolute values in the double-digit range is the parotid gland (14), which corresponds to a percentage of $4.9 \%$. Only 8 tumors (2.8\%) were located in the area of the epipharynx. 6 tumors (2.1\%) were found in the subglottic space, 4 tumors (1.4\%) originated from the lip, 2 tumors ( $0.7 \%$ ) were present in the area of the nose, ear, the submandibular gland and other skin areas in the head and neck area; 4 records (1.4\%) are unknown (-Table 4).

It can be noted that ultrasound detects most sensitively neck metastases and confirms the correct negative (unobtrusive) lymph nodes.

If the combination of ultrasound and clinical examination is then compared with CT/MRI imaging, it can also be seen that the combination "sonography and clinical investigation" with a positive likelihood ratio between 2.39 for ultrasound and 2.24 for clinical examination is significantly better than the result of CT/MRI examinations with the value of 2.10 and, thus, the cost-effective variants also offer an advantage over the more cost-intensive techniques ( - Table 3 ).

The diagnostic significance of the individual investigations with regard to therapy planning is determined by the positive and negative predictive value. With these two statistical parameters, the question of a neck dissection should be answered individually for each individual patient.

To be able to assess the results obtained in this work as far as possible, 14 publications are used for comparison, which were published between 1998 and 2017. There are only 3 statistical 
182 Comparison of Clinical Examination and Various Imaging Modalities Schneider et al.

Table 3 Comparison of the different diagnostic tools using 6 statistical parameters

\begin{tabular}{|l|l|l|l|l|l|l|}
\hline & SENS & SPEC & PPV & NPV & PLR & DA \\
\hline Clinical examination & 0.7576 & $\underline{0.6612}$ & 0.7530 & 0.6667 & 2.24 & 0.7168 \\
\hline Ultrasound & $\underline{0.9152}$ & 0.6167 & $\underline{0.7665}$ & $\underline{0.8409}$ & $\underline{2.39}$ & $\underline{0.7895}$ \\
\hline CT/MRI & 0.7866 & 0.6250 & 0.7414 & 0.6818 & 2.10 & 0.7183 \\
\hline
\end{tabular}

Abbreviations: DA, diagnostic accuracy; NPV, negative predictive value; PLR, positive likelihood ratio; PPV, positive predictive value; SENS,

Sensitivity; SPEC, Specificity.

Table 4 The most common locations of the primary tumor $(n=286)$

\begin{tabular}{|l|l|}
\hline Localization & Number (absolute values) of the primary tumors \\
\hline Oropharynx (35.3\%) & 101 \\
\hline Glottis (14.0\%) & 40 \\
\hline Lymph/Hematologic system (10.1\%) & 29 \\
\hline Oral cavity (8.4\%) & 24 \\
\hline Hypopharynx (8.4\%) & 24 \\
\hline Supraglottic area (8.4\%) & 24 \\
\hline Gl. Parotis (4.9\%) & 14 \\
\hline Epipharynx (2,8\%) & 8 \\
\hline Subglottic area (2,1\%) & 6 \\
\hline Skin: Lips (1,4\%) & 4 \\
\hline Skin: Nose (0,7\%) & 2 \\
\hline Skin: Ear (0,7\%) & 2 \\
\hline Skin: not further described (0,7\%) & 2 \\
\hline Gl. Submandibularis $(0,7 \%)$ & 2 \\
\hline No information (1.4\%) & 4 \\
\hline
\end{tabular}

Table 5 Comparison of statistical parameters in various publications (all values in \%)

\begin{tabular}{|c|c|c|c|c|c|c|c|c|c|c|}
\hline & Year & $\begin{array}{l}\text { DA } \\
\text { Clinic }\end{array}$ & $\begin{array}{l}\text { DA } \\
\text { Sono }\end{array}$ & $\begin{array}{l}\text { DA } \\
\text { CT/MRI }\end{array}$ & $\begin{array}{l}\text { SENS } \\
\text { Clinic }\end{array}$ & $\begin{array}{l}\text { SENS } \\
\text { Sono }\end{array}$ & $\begin{array}{l}\text { SENS } \\
\text { CT/MRI }\end{array}$ & $\begin{array}{l}\text { SPEC } \\
\text { Clinic }\end{array}$ & $\begin{array}{l}\text { SPEC } \\
\text { Sono }\end{array}$ & $\begin{array}{l}\text { SPEC } \\
\mathrm{CT} / \mathrm{MRI}\end{array}$ \\
\hline Adams et al ${ }^{4}$ & 1998 & - & 70.0 & $85.0 / 79.0$ & - & 72.0 & $82.0 / 80.0$ & - & 70.0 & $85.0 / 79.0$ \\
\hline Giancarlo et al $^{5}$ & 1998 & 81.1 & 81.1 & - & 82.1 & 82.1 & - & 80.0 & 80.0 & - \\
\hline van Veen et $\mathrm{al}^{6}$ & 2001 & - & - & 72.0 & - & - & 71.0 & - & - & 73.0 \\
\hline Haberal et al ${ }^{7}$ & 2004 & 75.0 & 85.0 & - & 64.0 & 72.0 & - & 85.0 & 96.0 & - \\
\hline King et $\mathrm{al}^{8}$ & 2004 & - & 85.0 & $92.0 / 91.0$ & - & 77.0 & $91.0 / 93.0$ & - & 93.0 & $93.0 / 89.0$ \\
\hline Akoglu et al ${ }^{9}$ & 2005 & - & 75.6 & $\begin{array}{l}80.4 / \\
70.7\end{array}$ & - & 81.4 & $77.7 / 59.2$ & - & 64.2 & $85.7 / 92.8$ \\
\hline Leicher-Düber et al ${ }^{10}$ & 2008 & 85.0 & 90.0 & - & 74.0 & 90.0 & - & 94.0 & 90.0 & - \\
\hline Danninger et al ${ }^{11}$ & 2008 & - & 78.0 & - & - & 96.0 & - & - & 69.0 & - \\
\hline Steinkamp et al ${ }^{12}$ & 2008 & 85.0 & 97.5 & - & 75.0 & 93.0 & - & 83.0 & 94.0 & - \\
\hline Liao et $\mathrm{al}^{13}$ & 2012 & - & - & - & - & 66.0 & $52.0 / 65.0$ & - & 78.0 & $93.0 / 81.0$ \\
\hline Shetty et al ${ }^{2}$ & 2015 & 72.4 & 76.9 & - & 36.6 & 54.5 & - & 86.6 & 85.7 & - \\
\hline Park et al ${ }^{14}$ & 2016 & - & 87.7 & $85.5 / 84.4$ & - & 44.8 & $48.3 / 41.4$ & - & - & - \\
\hline Sohn et al ${ }^{15}$ & 2016 & - & - & - & - & - & 54.6 & - & - & - \\
\hline Machado et al ${ }^{16}$ & 2017 & - & 91.0 & - & - & 96.4 & - & - & 85.7 & - \\
\hline Own results & & 71.7 & 79.0 & 71.8 & 75.8 & 91.5 & 78.7 & 66.1 & 61.7 & 62.5 \\
\hline
\end{tabular}

Abbreviations: DA, diagnostic accuracy; SENS, Sensitivity; SPEC, Specificity. 


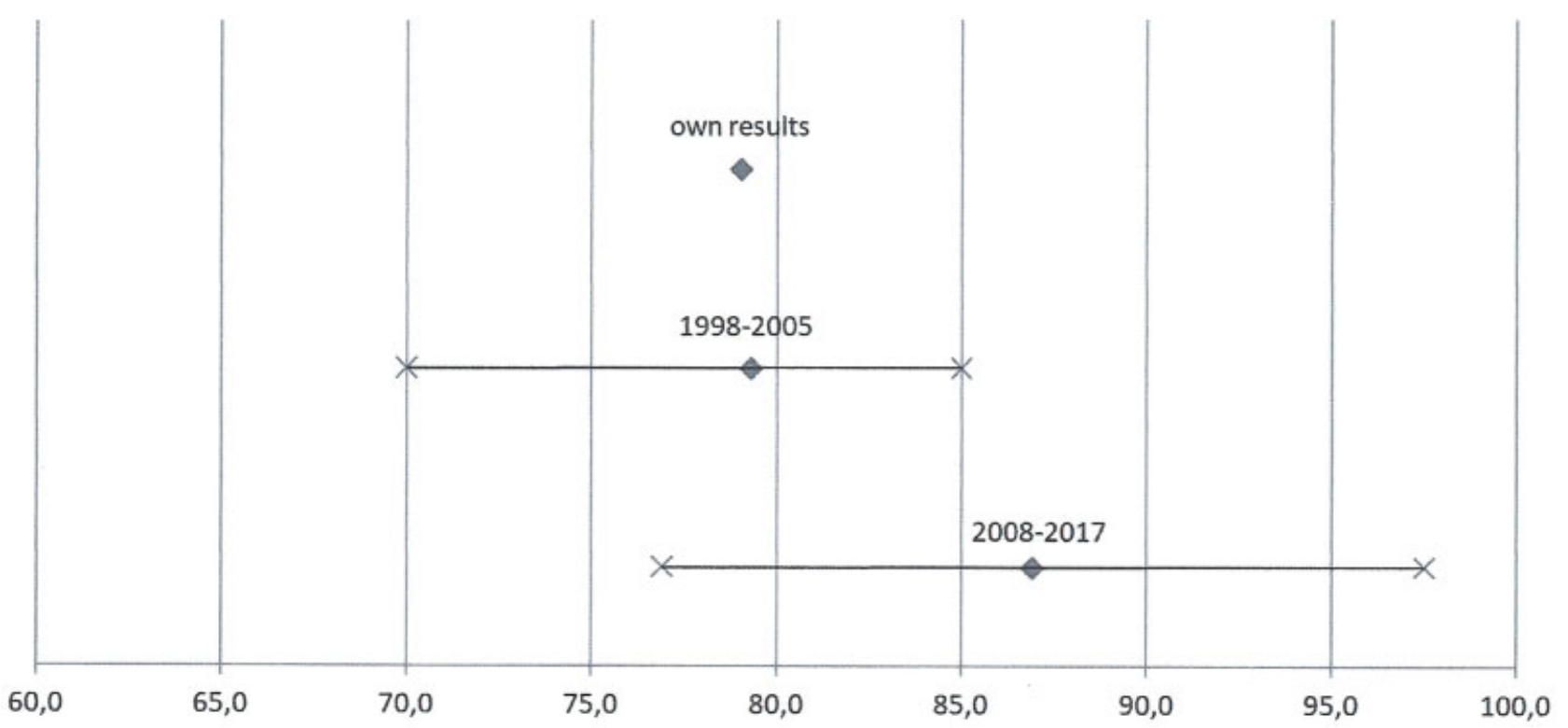

Fig. 1 Diagnostic accuracy of ultrasound (all values in \%, publications from 1998-2017).

parameters that differ when comparing the periods between 1998 and 2005 and between 2008 and 2017 (-Table 5).

The diagnostic accuracy of ultrasound in the period between 1998 and 2005 was between $70.0 \%$ and $85.0 \%$, ${ }^{4,5,7-9}$ whereas in the period between 2008 and 2017 the values were between $76.9 \%$ and $97.5 \%$. $2,10-12,14,16$ This is most likely due to the fact that the more recent devices have a much better resolution.

Clinical sensitivity was better in the period between 1998 and $2005(64.0-82.1 \%)^{5,7}$ than in the more recent studies (36.6-75.0\%). 2,10,12 This is due to the fact that, in the work of Shetty et $\mathrm{al}^{2}$, only $36.6 \%$ were calculated. The comparability of Shetty to the remaining studies is limited because only 26 patients with oral cancer have been studied there.

The sensitivity of the CT/MRI was calculated to be much higher in the period between 1998 and 2005 (59.2-93.0\%) 4,6,8,9 than in the period between 2008 and 2017 (41.4$65.0 \%) .{ }^{13-15}$ The studies of Liao, Park and Sohn ${ }^{13-15}$ are not comparable with the period between 1998 and 2005 and our own results. Liao ${ }^{13}$ only examined patients with cN0 status, which means that the lymph nodes do not carry any malignant cells. The study by Park et $\mathrm{al}^{14} 2016$ included only squamous cell carcinomas that were metastasized to the level VI. The study of Sohn ${ }^{15}$ only examined squamous cell carcinomas of the oropharynx with no palpable cervical lymph nodes.

Otherwise, the results from the period between 1998 and 2005 are very similar to the results from between 2008 and 2017 and to our own work. Because of this fact, the whole period from 1998 to 2017 was compared with our own results (-Fig. 1 ).

\section{Conclusion}

Ultrasound has the highest sensitivity (91.5\%), the best positive likelihood ratio (2.39), and the highest diagnostic accuracy (79.0\%). Accordingly, ultrasound is very sensitive but has only a relatively low specificity (61.7\%). In terms of test validity, ultrasound imaging provides the best results, which means that this method is the safest way to detect metastases.

With a positive predictive value of $76.7 \%$ and a negative predictive value of $84.1 \%$, ultrasound also produces the best results compared with the other diagnostic tools. The individual treatment planning of the patient is therefore largely dependent on the result of the ultrasound and influences decisively the decision to perform a neck dissection.

According to a meta-analysis performed by the National Institutes of Health (NIH) in which 63 studies were examined and compared, the CT scan has a higher sensitivity than the MRI. ${ }^{3}$ In addition to unsatisfactory sensitivity and specificity, the clinical study provides false-positive results in between 25 and $51 \%$ of the cases. Therefore, CT is a reliable diagnostic tool and plays an important role in the detection of neck metastases. ${ }^{3,10}$

In addition, CT findings are usually seen twice and only then released. After a radiological resident has examined the CT scan, he is subsequently validated by a specialist and/or a senior physician. This fact improves the examination procedure and ensures fewer false diagnoses.

The clinical examination, ultrasound and MRI are superior to CT in terms of X-Ray exposure. However, recently, it was published that Gadolinium is enriched in areas of the brain. ${ }^{17-19}$ Even though the effects have not yet been fully investigated, there is some potential damage by this investigation. Therefore, the CT scan is disadvantageous and MRI at least controversial compared with clinical examination and ultrasound.

Conflicts of interests

The authors declare that there are no conflicts of interests. 


\section{References}

1 Ohmura G, Tsujikawa T, Yaguchi T, et al. Aberrant Myosin 1b Expression Promotes Cell Migration and Lymph Node Metastasis of HNSCC. Mol Cancer Res 2015;13(04):721-731

2 Shetty D, Jayade BV, Joshi SK, Gopalkrishnan K. Accuracy of palpation, ultrasonography, and computed tomography in the evaluation of metastatic cervical lymph nodes in head and neck cancer. Indian J Dent 2015;6(03):121-124

3 Sun J, Li B, Li CJ, et al. Computed tomography versus magnetic resonance imaging for diagnosing cervical lymph node metastasis of head and neck cancer: a systematic review and meta-analysis. OncoTargets Ther 2015;8:1291-1313

4 Adams S, Baum RP, Stuckensen T, Bitter K, Hör G. Prospective comparison of 18F-FDG PET with conventional imaging modalities (CT, MRI, US) in lymph node staging of head and neck cancer. Eur J Nucl Med 1998;25(09):1255-1260

5 Giancarlo T, Palmieri A, Giacomarra V, Russolo M. Pre-operative evaluation of cervical adenopathies in tumours of the upper aerodigestive tract. Anticancer Res 1998;18(4B):2805-2809

6 van Veen SA, Balm AJ, Valdés Olmos RA, et al. Occult primary tumors of the head and neck: accuracy of thallium 201 singlephoton emission computed tomography and computed tomography and/or magnetic resonance imaging. Arch Otolaryngol Head Neck Surg 2001;127(04):406-411

7 Haberal I, Celik H, Göçmen H, Akmansu H, Yörük M, Ozeri C. Which is important in the evaluation of metastatic lymph nodes in head and neck cancer: palpation, ultrasonography, or computed tomography? Otolaryngol Head Neck Surg 2004;130(02):197-201

8 King AD, Tse GM, Ahuja AT, et al. Necrosis in metastatic neck nodes: diagnostic accuracy of CT, MR imaging, and US. Radiology 2004;230(03):720-726

9 Akoğlu E, Dutipek M, Bekiş R, Değirmenci B, Ada E, Güneri A. Assessment of cervical lymph node metastasis with different imaging methods in patients with head and neck squamous cell carcinoma. J Otolaryngol 2005;34(06):384-394

10 Leicher-Düber A, Bleier R, Düber C, et al. Halslymphknotenmetastasen: Histologisch kontrollierter Vergleich von Palpation,
Sonographie und Computertomographie. Fortschr Röntgenstr. 2008;153(11):575-579

11 Danninger R, Posawetz W, Humer U, Stammberger H, Jakse R. Ultraschalluntersuchung zervikaler Lymphknotenmetastasen: Konzept und Ergebnis einer histopathologischen Aufarbeitung. Laryngorhinootologie 1999;78(03):144-149

12 Steinkamp HJ, Knöbber D, Schedel H, Mäurer J, Felix R. Palpation und Sonographie in der Nachsorge von Kopf-Hals-Tumorpatienten: Vergleich sonographischer Dignitätsparameter. Laryngorhinootologie 1993;72(09):431-438

13 Liao LJ, Lo WC, Hsu WL, Wang CT, Lai MS. Detection of cervical lymph node metastasis in head and neck cancer patients with clinically N0 neck-a meta-analysis comparing different imaging modalities. BMC Cancer 2012;12:236

14 Park HS, Chung EJ, Park MW, et al. Usefulness of radiologic examinations for diagnosing level VI lymph node metastasis in patients with laryngohypopharyngeal carcinoma. Eur Arch Otorhinolaryngol 2016;273(11):3959-3964

15 Sohn B, Koh YW, Kang WJ, Lee JH, Shin NY, Kim J. Is there an additive value of 18 F-FDG PET-CT to CT/MRI for detecting nodal metastasis in oropharyngeal squamous cell carcinoma patients with palpably negative neck? Acta Radiol 2016;57(11):1352-1359

16 Machado MR, Tavares MR, Buchpiguel CA, Chammas MC. Ultrasonographic Evaluation of Cervical Lymph Nodes in Thyroid Cancer. Otolaryngol Head Neck Surg 2017;156(02):263-271

17 Stojanov D, Aracki-Trenkic A, Benedeto-Stojanov D. Gadolinium deposition within the dentate nucleus and globus pallidus after repeated administrations of gadolinium-based contrast agentscurrent status. Neuroradiology 2016;58(05):433-441

18 Murata N, Gonzalez-Cuyar LF, Murata K, et al. Macrocyclic and Other Non-Group 1 Gadolinium Contrast Agents Deposit Low Levels of Gadolinium in Brain and Bone Tissue: Preliminary Results From 9 Patients With Normal Renal Function. Invest Radiol 2016;51(07):447-453

19 Malayeri AA, Brooks KM, Bryant LH, et al. National Institutes of Health Perspective on Reports of Gadolinium Deposition in the Brain. J Am Coll Radiol 2016;13(03):237-241 